\title{
Multi-Scale Wavelet Transform Filtering of Non-Uniform Pavement \\ Surface Image Background for Automated Pavement Distress \\ Identification
}

\author{
Lu Sun ${ }^{1,2,3} \quad$ Zedong Qian ${ }^{3,4}$ \\ ${ }^{1}$ School of Architecture and Civil Engineering \\ Xiamen University, Xiamen, China \\ Email: workingworking123@163.com \\ ${ }^{2}$ Department of Civil Engineering \\ Catholic University of America, Washington D.C. 20064 \\ Email:sunl@cua.edu \\ ${ }^{3}$ School of Transportation \\ Southeast University, Nanjing, China \\ Email: workingworking123@163.com
}

${ }^{4}$ Shanghai Municipal Engineering Design Institute (Group) Co, LTD

Shanghai, P.R. China, 200092

Email:chienzedong@163.com 
Abstract: Non-uniform background of pavement images results in difficulties when segmenting pavement images for pavement distress identification. A novel and fast non-uniform background removal algorithm based on multi-scale wavelet transform is presented. The algorithm uses multi-scale wavelet transform to decompose pavement image and then reconstructs image background using low-wavenumber components through inverse wavelet transform. Brightness of image background is then corrected to achieve uniform background pavement image. The multi-scale wavelet transform algorithm is compared with median filter algorithm and morphological closing algorithm. Experimental results show that the proposed algorithm possesses the advantage of extracting tiny cracks more effectively than the other two algorithms, demonstrating its suitability to be used in automated pavement distress segmentation and identification.

Keywords: pavement distress; image processing; uniform background; multi-scale wavelet transform 


\section{Introduction}

Since the 1990s, the primary role of transportation agencies of the state has shifted from constructing new roads to managing these infrastructures (NSF 1993, Kane and Micozzi 1996, Charles and Rosser 2001). As of 2002 the U.S. Department of Transportation managed 6.41 million lane kilometers highways (World 2004). A drastic grow in highway mileage appears recently in China as well (Xu 2012). As a result, pavement management aiming at maintaining pavements at an acceptable condition in a cost-effective manner has been greatly highlighted by government agencies, the industry and the research community.

Pavement distresses are caused by aging, traffic loading, temperature fluctuation, moisture variation, etc. If pavement distresses are not detected and repaired in a timely manner, pavement performance gets deteriorated quickly and the service life of pavement can be shortened considerably. Therefore, timely detection and quantitative evaluation of pavement distress through the so-called pavement condition monitoring and assessment process are of great significance to maintaining high-quality pavement, elongating pavement service life and reducing life-cycle pavement maintenance cost.

Pavement condition monitoring and assessment consists of visual survey and pavement distress evaluation. It involves the following steps: (i) Divide the road into a number of pavement sections of size approximately 5000 square feet for each section. (ii) Based on the total number of pavement sections, a certain percentage (usually less than 10\%) are randomly selected as sample units. (iii) Sample units of pavement sections are surveyed to specify pavement distress type, extent (i.e., spatial density) and severity (e.g., low, medium, and severe) in each section using distress definitions outlined in ASTM Standard D5340 (2004). (iv) Pavement Condition Index is 
computed as a weight average of distresses, in which different distress type, density and severity correspond to different weight factors and values of deduction.

Traditionally, visual survey is conducted manually. A team of trained pavement engineers (raters) are sent to the field and manually record pavement distresses according to ASTM Standard D5340. For years, the process of manual surveys has generated a lot of safety, consistency, and efficiency concerns. Raters are at risk as they are on the roads and exposed to running traffic during a manual survey. Manual survey is also subjective, and different raters may produce different rating on an identical pavement image. In addition, manual survey is very slow, time consuming, incapable of surveying thousands of miles of roads in a timely manner.

Nowadays, emerging digital camera technology has evolved with line scan digital cameras beginning to replace area scan digital cameras used to produce downward-facing images (Sokolic et al. 2004). Image acquisition technology based on charge coupled device (CCD) has been used as well in automated visual survey with its advantages of high-speed and high-resolution (Georgopoulos et al. 1995, Huang and Xu 2006). Commercially available video recording systems mounted on an instrumented vehicle are now capable of producing downward-facing high-resolution images at a highway speed, achieving $1 \mathrm{~mm}$ crack identification while traveling at $80 \sim 100 \mathrm{~km} / \mathrm{h}$. This level of resolution enables the majority of pavement distress to be recorded accurately (Cheng and Glazier 2002).

Automated visual survey produces a continuous rolling display of frames of pavement surface image. Each frame of the image typically covers the width of an entire lane with a fixed length of $3.5 \sim 4.3 \mathrm{~m}$. Pavement condition assessment is thus based on the rating of each individual frame of pavement surface image. Automated surveying allows the majority of pavement distresses to be recorded accurately, safely, 
consistently, and efficiently. An automated survey costs half as much as a manual one, promising to lead the future trend for pavement maintenance management. With these advantages, automated visual survey is becoming a more popular option for many transportation agencies (National 2004). A few prototype automated survey systems have been developed (Smadi et al. 1997, Oh 1998, Wang and Elliot 1999, Wang 2000, 2003, Sivaneswaran and Pierce 2001, Sjogren 2002, Cheng and Glazier 2002, Javidi et al. 2003, Gunaratne 2003, Chung et al. 2003, Lindly et al. 2005, Acosta et al. 2004).

Although automated survey is no longer an obstacle to pavement condition assessment, compelling challenges remain in automated pavement distress identification and evaluation. Currently, most pavement distress evaluation is still done by having trained raters manually evaluate in laboratory the automatically collected surface images of sampled pavement sections. The process suffers from subjective rating, poor consistency and long data processing time (Ward et al. 1992, Cheng and Mivojim 1998, Ferguson et al. 1999, Huang and Xu 2006, Kamaliardakani and Sun 2014, Sun et al. 2015). Due to severe deterioration of national transportation infrastructure and tight road maintenance budget, automated pavement distress identification and evaluation have benefits that hardly need additional explanation.

\section{Literature Review}

In automated visual survey of pavement surface, images with non-uniform background are commonly collected. Non-uniformity in images is often caused by distributed lighting condition, dirt on pavement surface, shadow and foreign objects. Obtaining pavement images with uniform background is critical to a successful segmentation of pavement images and to a high accuracy of automated pavement 
distresses identification.

Since late 1990s a few studies have devoted to address this obstacle. Koutsopoulos and Downey created an ideal pavement background image using pixel-by-pixel average of a few pavement images with no distresses. The ideal background image is subtracted from the original image to obtain a subtracted image with uniform background. In order to avoid the negative values, a positive constant is added to the subtracted image (Koutsopoulos and Downey 1993).

Cheng and Mivojim presented an enhancement algorithm which corrects non-uniform background by multiplication factors. Each pavement image is divided into rectangle windows and the mean value of each window is calculated. The multiplication factor for each rectangle window is obtained by transferring the mean value of each rectangle window to the mean value of the whole pavement image. In order to calculate accurate multiplication factor, the mean value of each rectangle window with cracks should be replaced by the average value of the mean values of two adjacent rectangle windows without cracks (Cheng and Mivojim 1998). Based on Cheng's work, Ying proposed a new non-uniform background removal method by calculating the mean, minimum and maximum gray level of each rectangle window, and setting an upper limit and a lower limit for each rectangle window. The pixels with gray level between the lower limit and the upper limit are considered as the background pixels (Ying 2009). Cheng et al. further used an un-sharp masking method to removal the non-uniform background intensity effect by subtracting a blurred image from the original image. The blurred image can be obtained by convoluting a low-pass spatial filter with the original image (Cheng et al.1999).

Zhou et al. (2003) used Daubechies wavelet of the second order to decompose a pavement image into three levels. Based on the statistical models in the wavelet 
domain, several detection and isolation criteria (i.e., HAWCP, the HFEP, and STD) are proposed to recognize pavement images with distress. However, this work cannot extract the pixels of pavement distress from the pavement images and the width, length and area of pavement distress cannot be obtained by the proposed method. The pavement image reconstructed using the inverse wavelet transform is not considered in the study.

Sun et al. used a Gaussian low-pass spatial filter to avoid a bright ringing effect (Sun et al.2009). Salari et al. introduced a new method of obtaining the blurred image by performing erosion operation followed dilatation operation with the same structuring element, which is also called morphological closing (Salari et al.2010). Chou and Salari extracted the background of the pavement images by applying a relative large size median filter to images for eliminating the detailed information on pavement surface (Chou and Salari 2012). Huang and Tsai also used the median filter to obtain the background of pavement images, but a positive constant is added to the subtracted image to avoid the negative values when the background image is subtracted from the original image (Huang and Tsai 2011).

It is evident that the existing methods for obtaining a uniform pavement image background mainly use filters in the spatial domain. As a result, a relatively large size filter needs to be used, which may lead to a reduced efficiency of the algorithm. Another disadvantage of spatial domain filter is that low-frequency background may not be effectively separated from high-frequency details effectively without losing some critical information that is essential for the identification of pavement distresses. In this study a multi-scale wavelet transform filter in the wavelet domain is used to decompose pavement images into the wavelet domain. Specifically, Daubechies wavelet of the fourth order was used to decompose a distress image into eight levels 
of subband. Pavement image background is obtained by reconstructing the low-frequency component of pavement images using inverse wavelet transform. The main objective of this paper is to extract the pixels of pavement distress from the pavement images accurately so that the width, length and area of pavement distress can be obtained, which is indispensable for evaluating pavement condition. Experimental results show that our algorithm possesses the advantage of extracting tiny cracks more effectively than two existing algorithms: median filter and morphological closing.

\section{Algorithm Design}

Pavement images are usually composed of background, distress, and noise. The background is the low-wavenumber components from wavenumber domain perspective, while the distress and noise are the high-wavenumber components. Non-uniform brightness of pavement images is mainly caused by the non-uniform background. Therefore, it is critical to obtain uniform brightness pavement images of which the background is separated from pavement images and its brightness is corrected.

This paper uses the method of multi-scale wavelet transform to extract the background of pavement image. A pavement image can be decomposed into different wavenumber subbands by the wavelet transform and the background is in lowwavenumber subbands. This algorithm uses multi-scale wavelet transform to decompose the pavement image, then the background can be obtained by reconstructing the low-wavenumber component of pavement images.

This algorithm is designed to correct brightness of pavement background image to a more uniform one. The algorithm consists of the following steps. 
Step 1. Use multi-scale wavelet transform to decompose the pavement image and obtain the decomposition structure of pavement images.

Step 2. Reconstruct the low-wavenumber component (image background) of pavement images by the inverse wavelet transform.

Step 3. Compensate for the brightness of the image background. Because pavement images are grayscale image, the equation of compensating for brightness is

$$
\mathrm{B}=255-\mathrm{X},
$$

where $\mathrm{B}$ is compensation brightness of pavement image and $\mathrm{X}$ is the gray of the background.

Step 4. Obtain the uniform background pavement images by:

$$
\mathrm{J}=0.5 \times \mathrm{I}+0.5 \times \mathrm{B} \text {. }
$$

where $\mathbf{J}$ is the uniform background pavement image and $\mathrm{I}$ is the original pavement image. In wavelet transform the coefficients of the approximation and details are obtained by the inner product operation between the original image with a low-pass filter $h_{0}$ and a high-pass filter $h_{1}$ which are constructed from a scaling function and a wavelet function respectively. By using inverse wavelet transform, image reconstruction which is the inverse process of decomposition can be achieved. The process of image reconstruction is realized by taking inner product of the approximation and detail coefficients with two mirror filters of the decomposition filters.Pavement image $\mathrm{f}\left(\mathrm{x}_{1}, \mathrm{x}_{2}\right)$ is a two-dimensional function in a measurable and square integrable space $\mathrm{L}^{2}\left(\mathrm{R}^{2}\right)$. Let $\left\{\mathrm{V}_{\mathrm{j}}\left(\mathrm{x}_{1}, \mathrm{x}_{2}\right)\right\}_{\mathrm{j} \in \mathrm{Z}}$ represent a multi-resolution approximation of $\mathrm{L}^{2}\left(\mathrm{R}^{2}\right)$ and $\left\{\mathrm{W}_{\mathrm{j}}\left(\mathrm{x}_{1}, \mathrm{x}_{2}\right)\right\}_{\mathrm{j} \in \mathrm{Z}}$ denote a multi-resolution details of $\mathrm{L}^{2}\left(\mathrm{R}^{2}\right)$, where $\mathrm{j}=1,2,3, \ldots$, and $\mathrm{Z}$ is the natural number(Mallat 1989). The relationship in the two-dimensional multi-resolution analysis is as follow: 


$$
\begin{aligned}
& \mathrm{V}_{\mathrm{j}-1}\left(\mathrm{x}_{1}, \mathrm{x}_{2}\right)=\mathrm{V}_{\mathrm{j}}\left(\mathrm{x}_{1}, \mathrm{x}_{2}\right) \oplus \mathrm{W}_{\mathrm{j}}\left(\mathrm{x}_{1}, \mathrm{x}_{2}\right) \\
& \mathrm{W}_{\mathrm{j}}\left(\mathrm{x}_{1}, \mathrm{x}_{2}\right)=\mathrm{V}_{\mathrm{j}-1}\left(\mathrm{x}_{1}, \mathrm{x}_{2}\right) / \mathrm{V}_{\mathrm{j}}\left(\mathrm{x}_{1}, \mathrm{x}_{2}\right)
\end{aligned}
$$

where $\mathrm{W}_{\mathrm{j}}\left(\mathrm{x}_{1}, \mathrm{x}_{2}\right)$ is the complement of $\mathrm{V}_{\mathrm{j}}\left(\mathrm{x}_{1}, \mathrm{x}_{2}\right)$ in $\mathrm{V}_{\mathrm{j}-1}\left(\mathrm{x}_{1}, \mathrm{x}_{2}\right)$.If the twodimensional space $\mathrm{V}_{\mathrm{j}}\left(\mathrm{x}_{1}, \mathrm{x}_{2}\right)$ is separable, it can be decomposed into the tensor product of two one-dimensional space $\mathrm{V}_{\mathrm{j}}\left(\mathrm{x}_{1}\right)$ and $\mathrm{V}_{\mathrm{j}}\left(\mathrm{x}_{2}\right)$,

$$
\begin{aligned}
\mathrm{V}_{\mathrm{j}-1}\left(\mathrm{x}_{1}, \mathrm{x}_{2}\right)= & \mathrm{V}_{\mathrm{j}-1}\left(\mathrm{x}_{1}\right) \otimes \mathrm{V}_{\mathrm{j}-1}\left(\mathrm{x}_{2}\right) \\
= & {\left[\mathrm{V}_{\mathrm{j}}\left(\mathrm{x}_{1}\right) \oplus \mathrm{W}_{\mathrm{j}}\left(\mathrm{x}_{1}\right)\right] \otimes\left[\mathrm{V}_{\mathrm{j}}\left(\mathrm{x}_{2}\right) \oplus \mathrm{W}_{\mathrm{j}}\left(\mathrm{x}_{2}\right)\right] } \\
= & {\left[\mathrm{V}_{\mathrm{j}}\left(\mathrm{x}_{1}\right) \otimes \mathrm{V}_{\mathrm{j}}\left(\mathrm{x}_{2}\right)\right] \oplus\left[\mathrm{V}_{\mathrm{j}}\left(\mathrm{x}_{1}\right) \otimes \mathrm{W}_{\mathrm{j}}\left(\mathrm{x}_{2}\right)\right] \oplus } \\
& {\left[\mathrm{W}_{\mathrm{j}}\left(\mathrm{x}_{1}\right) \otimes \mathrm{V}_{\mathrm{j}}\left(\mathrm{x}_{2}\right)\right] \oplus\left[\mathrm{W}_{\mathrm{j}}\left(\mathrm{x}_{1}\right) \otimes \mathrm{W}_{\mathrm{j}}\left(\mathrm{x}_{2}\right)\right] } \\
= & \mathrm{V}_{\mathrm{j}}\left(\mathrm{x}_{1}, \mathrm{x}_{2}\right) \oplus \mathrm{W}_{\mathrm{j}}^{\mathrm{H}}\left(\mathrm{x}_{1}, \mathrm{x}_{2}\right) \oplus \mathrm{W}_{\mathrm{j}}^{\mathrm{V}}\left(\mathrm{x}_{1}, \mathrm{x}_{2}\right) \oplus \mathrm{W}_{\mathrm{j}}^{\mathrm{D}}\left(\mathrm{x}_{1}, \mathrm{x}_{2}\right)
\end{aligned}
$$

The image $\mathrm{f}_{\mathrm{j}-1}\left(\mathrm{x}_{1}, \mathrm{x}_{2}\right)$ can be decomposed by projecting the image in the space $\mathrm{V}_{\mathrm{j}}\left(\mathrm{x}_{1}, \mathrm{x}_{2}\right), \mathrm{W}_{\mathrm{j}}^{\mathrm{H}}\left(\mathrm{x}_{1}, \mathrm{x}_{2}\right), \mathrm{W}_{\mathrm{j}}^{\mathrm{V}}\left(\mathrm{x}_{1}, \mathrm{x}_{2}\right)$ and $\mathrm{W}_{\mathrm{j}}^{\mathrm{D}}\left(\mathrm{x}_{1}, \mathrm{x}_{2}\right) . \mathrm{H}, \mathrm{V}$, and $\mathrm{D}$ represent the horizontal, vertical, and diagonal direction respectively,

$$
\begin{aligned}
\mathrm{f}_{\mathrm{j}-1}\left(\mathrm{x}_{1}, \mathrm{x}_{2}\right)= & \sum_{\mathrm{n}_{1}, \mathrm{n}_{2}} \mathrm{LL}_{\mathrm{j}}\left(\mathrm{n}_{1}, \mathrm{n}_{2}\right) \phi\left(2^{\mathrm{j}} \mathrm{x}_{1}-\mathrm{n}_{1}, 2^{\mathrm{j}} \mathrm{x}_{2}-\mathrm{n}_{2}\right)+ \\
& \sum_{\mathrm{n}_{1}, \mathrm{n}_{2}} \mathrm{HL}_{\mathrm{j}}\left(\mathrm{n}_{1}, \mathrm{n}_{2}\right) \psi^{\mathrm{H}}\left(2^{\mathrm{j}} \mathrm{x}_{1}-\mathrm{n}_{1}, 2^{\mathrm{j}} \mathrm{x}_{2}-\mathrm{n}_{2}\right)+ \\
& \sum_{\mathrm{n}_{1}, \mathrm{n}_{2}} \mathrm{LH}_{\mathrm{j}}\left(\mathrm{n}_{1}, \mathrm{n}_{2}\right) \psi^{\mathrm{v}}\left(2^{\mathrm{j}} \mathrm{x}_{1}-\mathrm{n}_{1}, 2^{\mathrm{j}} \mathrm{x}_{2}-\mathrm{n}_{2}\right)+ \\
& \sum_{\mathrm{n}_{1}, \mathrm{n}_{2}} \mathrm{HH}_{\mathrm{j}}\left(\mathrm{n}_{1}, \mathrm{n}_{2}\right) \psi^{\mathrm{D}}\left(2^{\mathrm{j}} \mathrm{x}_{1}-\mathrm{n}_{1}, 2^{\mathrm{j}} \mathrm{x}_{2}-\mathrm{n}_{2}\right)
\end{aligned}
$$

where $\phi\left(2^{\mathrm{j}} \mathrm{x}_{1}-\mathrm{n}_{1}, 2^{\mathrm{j}} \mathrm{x}_{2}-\mathrm{n}_{2}\right), \psi^{\mathrm{H}}\left(2^{\mathrm{j}} \mathrm{x}_{1}-\mathrm{n}_{1}, 2^{\mathrm{j}} \mathrm{x}_{2}-\mathrm{n}_{2}\right), \psi^{\mathrm{v}}\left(2^{\mathrm{j}} \mathrm{x}_{1}-\mathrm{n}_{1}, 2^{\mathrm{j}} \mathrm{x}_{2}-\mathrm{n}_{2}\right)$ and $\psi^{\mathrm{D}}\left(2^{\mathrm{j}} \mathrm{x}_{1}-\mathrm{n}_{1}, 2^{\mathrm{j}} \mathrm{x}_{2}-\mathrm{n}_{2}\right)$ are orthonormal bases in the space $\mathrm{V}_{\mathrm{j}}\left(\mathrm{x}_{1}, \mathrm{x}_{2}\right)$, $\mathrm{W}_{\mathrm{j}}^{\mathrm{H}}\left(\mathrm{x}_{1}, \mathrm{x}_{2}\right), \mathrm{W}_{\mathrm{j}}^{\mathrm{V}}\left(\mathrm{x}_{1}, \mathrm{x}_{2}\right)$ and $\mathrm{W}_{\mathrm{j}}^{\mathrm{D}}\left(\mathrm{x}_{1}, \mathrm{x}_{2}\right) . \mathrm{LL}_{\mathrm{j}}, \mathrm{HL}_{\mathrm{j}}, \mathrm{LH}_{\mathrm{j}}$ and $\mathrm{HH}_{\mathrm{j}}$ are the orthogonal projections in the space $\mathrm{V}_{\mathrm{j}}\left(\mathrm{x}_{1}, \mathrm{x}_{2}\right), \mathrm{W}_{\mathrm{j}}^{\mathrm{H}}\left(\mathrm{x}_{1}, \mathrm{x}_{2}\right), \mathrm{W}_{\mathrm{j}}^{\mathrm{V}}\left(\mathrm{x}_{1}, \mathrm{x}_{2}\right)$ and $\mathrm{W}_{\mathrm{j}}^{\mathrm{D}}\left(\mathrm{x}_{1}, \mathrm{x}_{2}\right)$. They can be obtained by the following equations: 


$$
\begin{aligned}
& \mathrm{LL}_{\mathrm{j}}\left(\mathrm{i}_{1}, \mathrm{i}_{2}\right)=\sum_{\mathrm{n}_{1}, \mathrm{n}_{2}} \mathrm{~h}_{0}\left(\mathrm{n}_{1}-2 \mathrm{i}_{1}\right) \mathrm{h}_{0}\left(\mathrm{n}_{2}-2 \mathrm{i}_{2}\right) L L_{\mathrm{j}-1}\left(\mathrm{n}_{1}, \mathrm{n}_{2}\right) \\
& \mathrm{HL}_{\mathrm{j}}\left(\mathrm{i}_{1}, \mathrm{i}_{2}\right)=\sum_{\mathrm{n}_{1}, \mathrm{n}_{2}} \mathrm{~h}_{1}\left(\mathrm{n}_{1}-2 \mathrm{i}_{1}\right) \mathrm{h}_{0}\left(\mathrm{n}_{2}-2 \mathrm{i}_{2}\right) L L_{\mathrm{j}-1}\left(\mathrm{n}_{1}, \mathrm{n}_{2}\right) \\
& \mathrm{LH}_{\mathrm{j}}\left(\mathrm{i}_{1}, \mathrm{i}_{2}\right)=\sum_{\mathrm{n}_{1}, \mathrm{n}_{2}} \mathrm{~h}_{0}\left(\mathrm{n}_{1}-2 \mathrm{i}_{1}\right) \mathrm{h}_{1}\left(\mathrm{n}_{2}-2 \mathrm{i}_{2}\right) L L_{\mathrm{j}-1}\left(\mathrm{n}_{1}, \mathrm{n}_{2}\right) \\
& \mathrm{HH}_{\mathrm{j}}\left(\mathrm{i}_{1}, \mathrm{i}_{2}\right)=\sum_{\mathrm{n}_{1}, \mathrm{n}_{2}} \mathrm{~h}_{1}\left(\mathrm{n}_{1}-2 \mathrm{i}_{1}\right) \mathrm{h}_{1}\left(\mathrm{n}_{2}-2 \mathrm{i}_{2}\right) L L_{\mathrm{j}-1}\left(\mathrm{n}_{1}, \mathrm{n}_{2}\right)
\end{aligned}
$$

Here $\mathrm{LL}_{0}$ denotes the original image and the reconstruction equation is

$$
\begin{aligned}
\mathrm{LL}_{\mathrm{j}-1}\left(\mathrm{i}_{1}, \mathrm{i}_{2}\right)= & \sum_{\mathrm{n}_{1}, \mathrm{n}_{2}} \mathrm{LL}_{\mathrm{j}}\left(\mathrm{n}_{1}, \mathrm{n}_{2}\right) \mathrm{h}_{0}\left(\mathrm{i}_{1}-2 \mathrm{n}_{1}\right) \mathrm{h}_{0}\left(\mathrm{i}_{2}-2 \mathrm{n}_{2}\right)+ \\
& \sum_{\mathrm{n}_{1}, \mathrm{n}_{2}} \mathrm{HL}_{\mathrm{j}}\left(\mathrm{n}_{1}, \mathrm{n}_{2}\right) \mathrm{h}_{1}\left(\mathrm{i}_{1}-2 \mathrm{n}_{1}\right) \mathrm{h}_{0}\left(\mathrm{i}_{2}-2 \mathrm{n}_{2}\right)+ \\
& \sum_{\mathrm{n}_{1}, \mathrm{n}_{2}} \mathrm{LH}_{\mathrm{j}}\left(\mathrm{n}_{1}, \mathrm{n}_{2}\right) \mathrm{h}_{0}\left(\mathrm{i}_{1}-2 \mathrm{n}_{1}\right) \mathrm{h}_{1}\left(\mathrm{i}_{2}-2 \mathrm{n}_{2}\right)+ \\
& \sum_{\mathrm{n}_{1}, \mathrm{n}_{2}} \mathrm{HH}_{\mathrm{j}}\left(\mathrm{n}_{1}, \mathrm{n}_{2}\right) \mathrm{h}_{1}\left(\mathrm{i}_{1}-2 \mathrm{n}_{1}\right) \mathrm{h}_{1}\left(\mathrm{i}_{2}-2 \mathrm{n}_{2}\right)
\end{aligned}
$$

In order to obtain a more ideal background of the pavement image, suitable wavelets and decomposition levels needs to be determined. In this study Daubechies wavelet of the fourth order was used to decompose a distress image into eight levels. An algorithm has been implemented in MATLAB R2008a through an embedded Image Processing Toolbox in a Windows environment (Intel(R) Core(TM) i5 CPU760 @ 2.80 GHz $1.18 \mathrm{GHz}, 3.50 \mathrm{~GB}$ RAM and OS Windows XP Professional).The background of the distress pavement images and the uniform background pavement images obtained by the wavelet transform in different level $j(j=1,2, \ldots, 8)$ are shown in Fig. 1 and Fig. 2, respectively. It is obvious that the more ideal uniform background pavement image is obtained by reconstructing low-wavenumber subband in 6 level.

It should be noted that this 6 level of subband is not a conclusion generally applicable to any non-uniform pavement background. Our pavement images under investigation are of size $2048 \times 3480$. When the pavement image size becomes is 
$1024 \times 1740$, the more ideal uniform background pavement image is obtained by reconstructing low-wavenumber subband in 5 level. Hence, the suitable level of reconstructing low-wavenumber subband is dependent on image size and should be determined though trial-and-error.
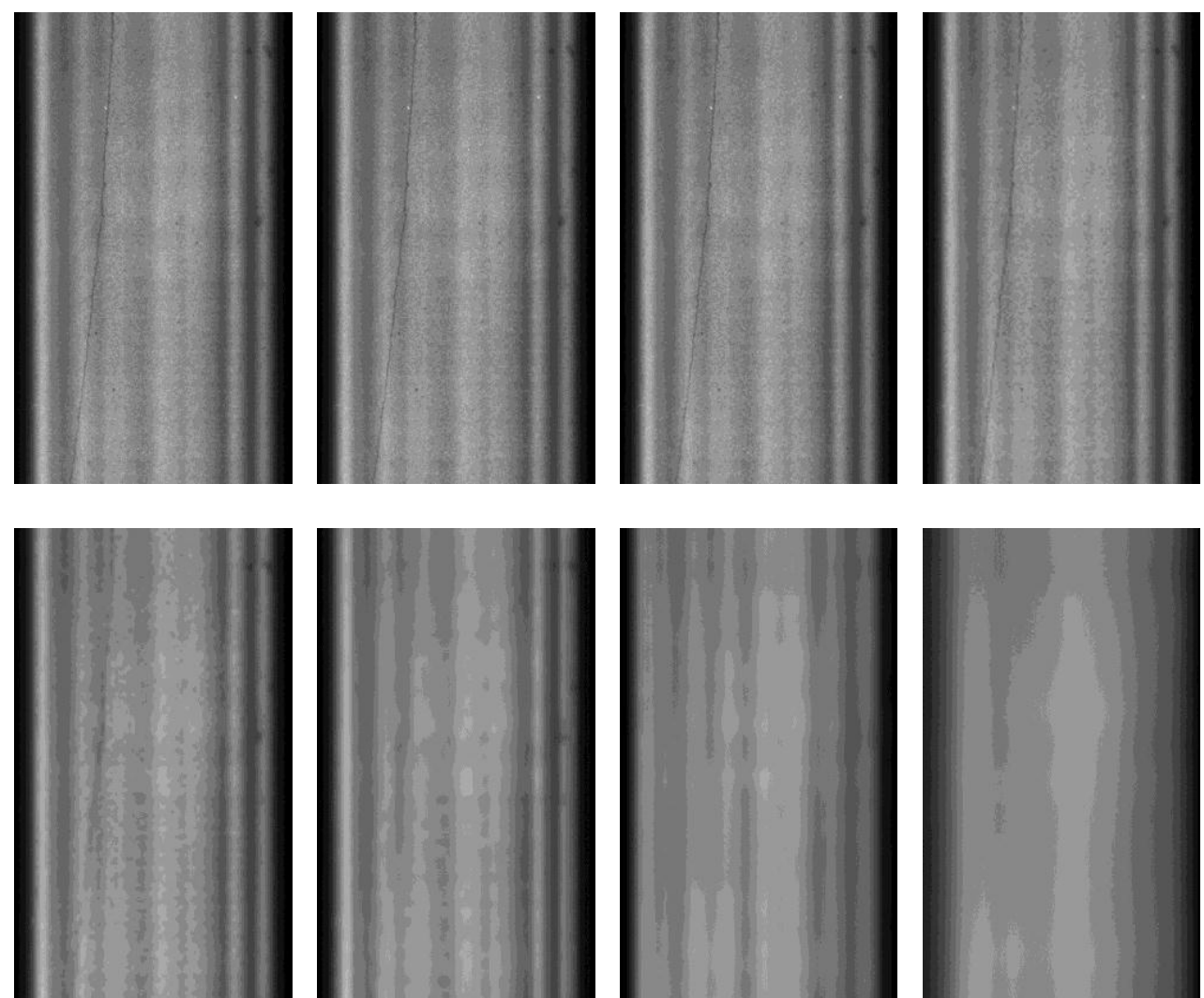

Figure 1. Background of pavement images obtained by wavelet transform in different scales $\mathrm{j}(\mathrm{j}=1,2, \ldots, 8)$
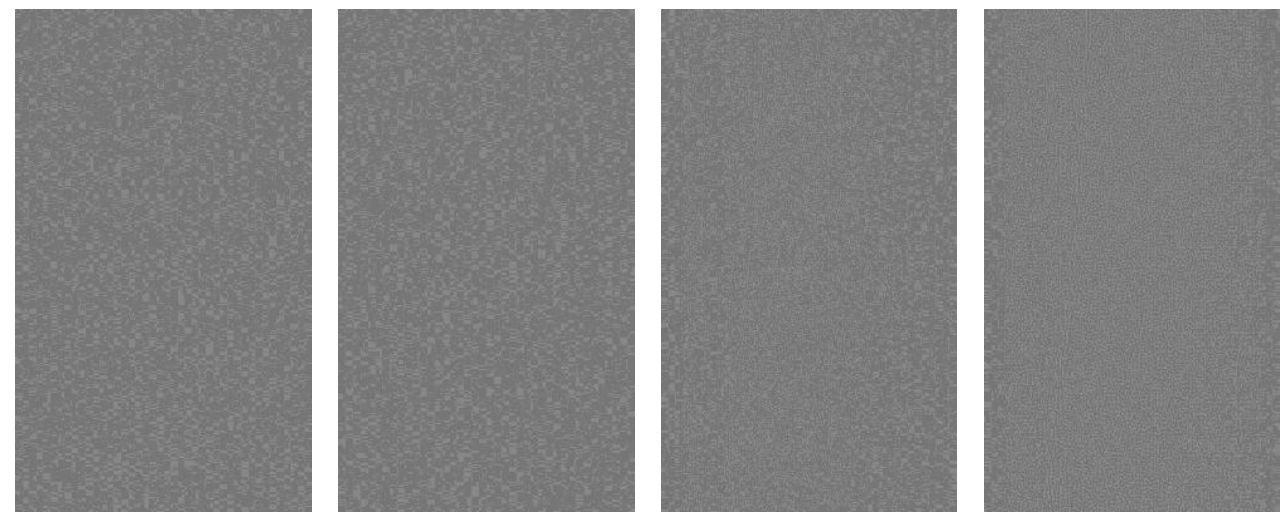

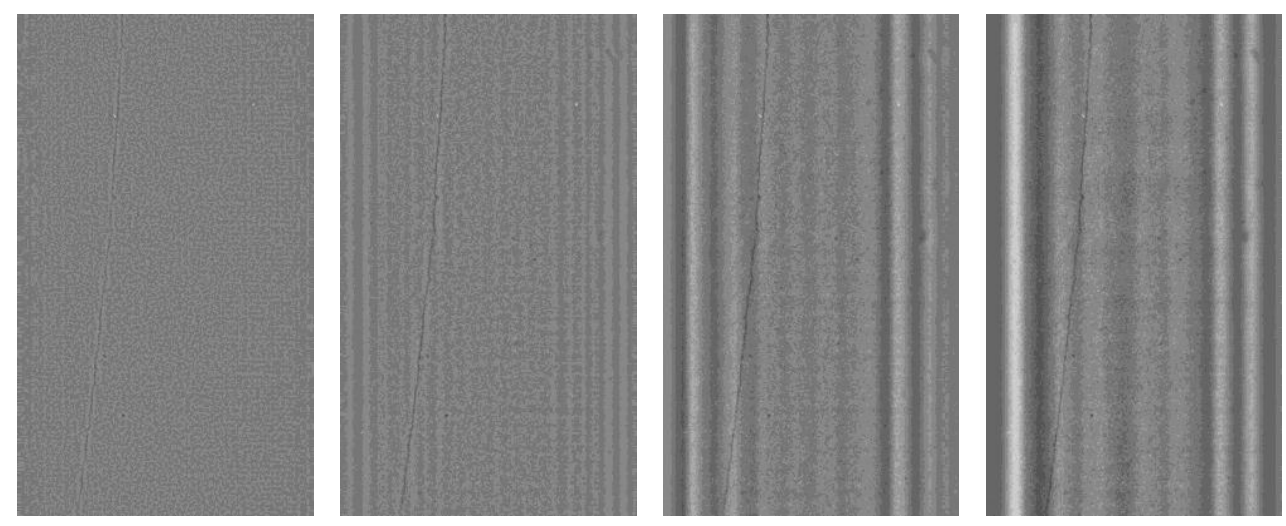

Figure 2. Uniform background pavement images obtained by wavelet transform in different scales $\mathrm{j}(\mathrm{j}=1,2, \ldots, 8)$

$\mathrm{LL}_{8}$ is the low-wavenumber subband and it is also called approximation. $\mathrm{HL}_{\mathrm{j}}$, $\mathrm{LH}_{\mathrm{j}}$ and $\mathrm{HH}_{\mathrm{j}}$ denote the high-frequency subbands in level $\mathrm{j}(\mathrm{j}=1,2, \ldots, 8)$, which are also called details in the horizontal, vertical, and diagonal direction. To get the background of pavement image, only the low-wavenumber coefficient of pavement image is reconstructed by setting $\mathrm{HL}_{\mathrm{j}}, \mathrm{LH}_{\mathrm{j}}$ and $\mathrm{HH}_{\mathrm{j}}$ to zero matrix in equation (11). The decomposition result in the view mode of tree is shown in Fig. 3(a), and it also can be shown in the view mode of square in Fig. 3(b). In order to be seen clearly, the decomposition result of Fig. 3(a) is enlarged as shown in Fig.4. It is easily seen that the crack information begins to become obscure from L6 and it can further verify the conclusion that the more ideal uniform background pavement image is obtained by reconstructing low-wavenumber subband in 6 level. Fig. 5 shows the original pavement image and the average gray level. These images are the original pavement image in Fig. 5 (a), the average gray level in the column direction in Fig. 5 (b), the average gray level in the row direction in Fig. 5 (c). Fig. 6 shows the result after a pavement image is implemented by the non-uniform background removal algorithm based on the multi-scale wavelet transform. These images are the uniform background pavement image in Fig. 6 (a), the average gray level in the column direction in Fig. 6 
(b), the average gray level in the row direction in Fig. 6 (c). It is easily seen that the uniform background pavement image can be obtained by the algorithm presented in this paper.

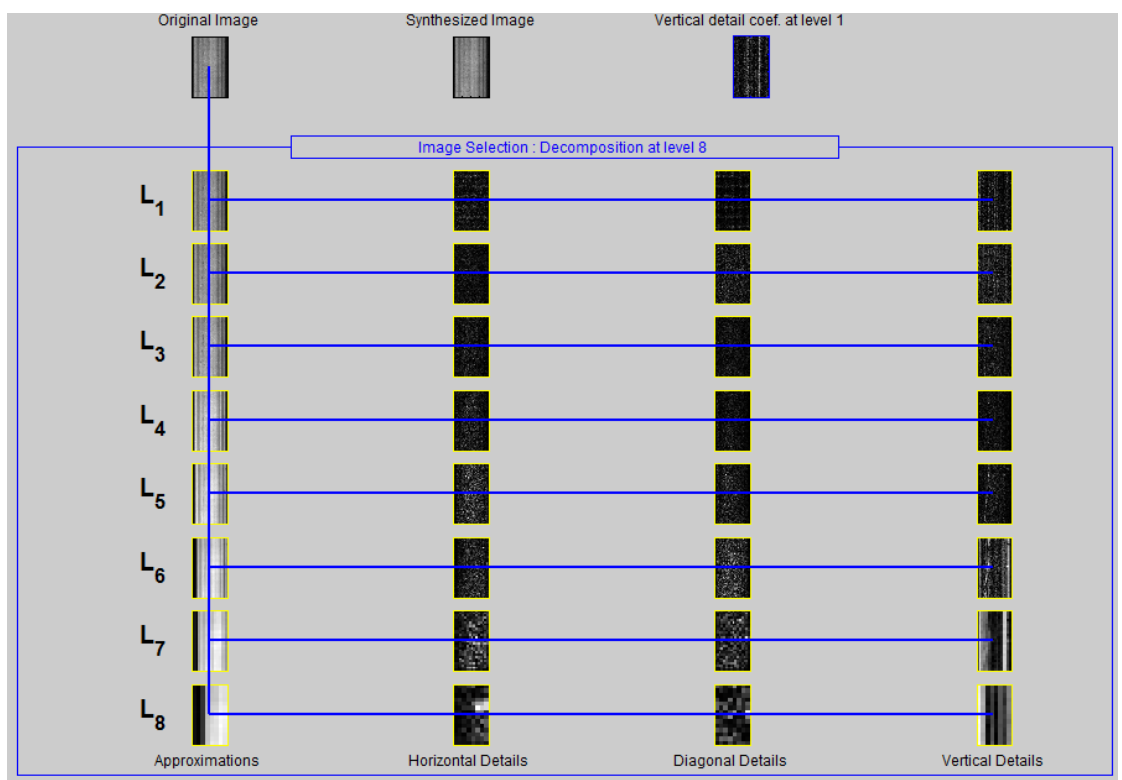

(a)

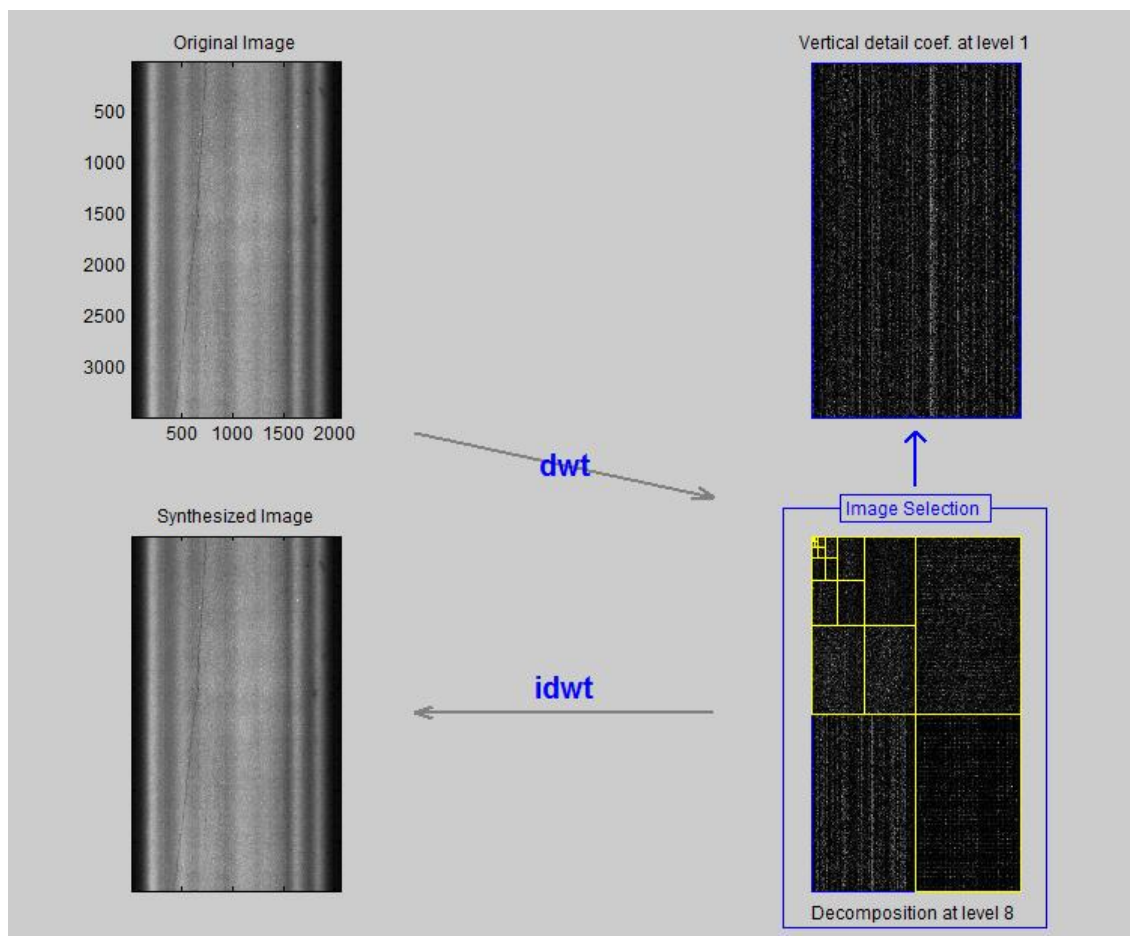

(b)

Figure 3. Decomposition and re-construction results using multi-scale wavelet transform 

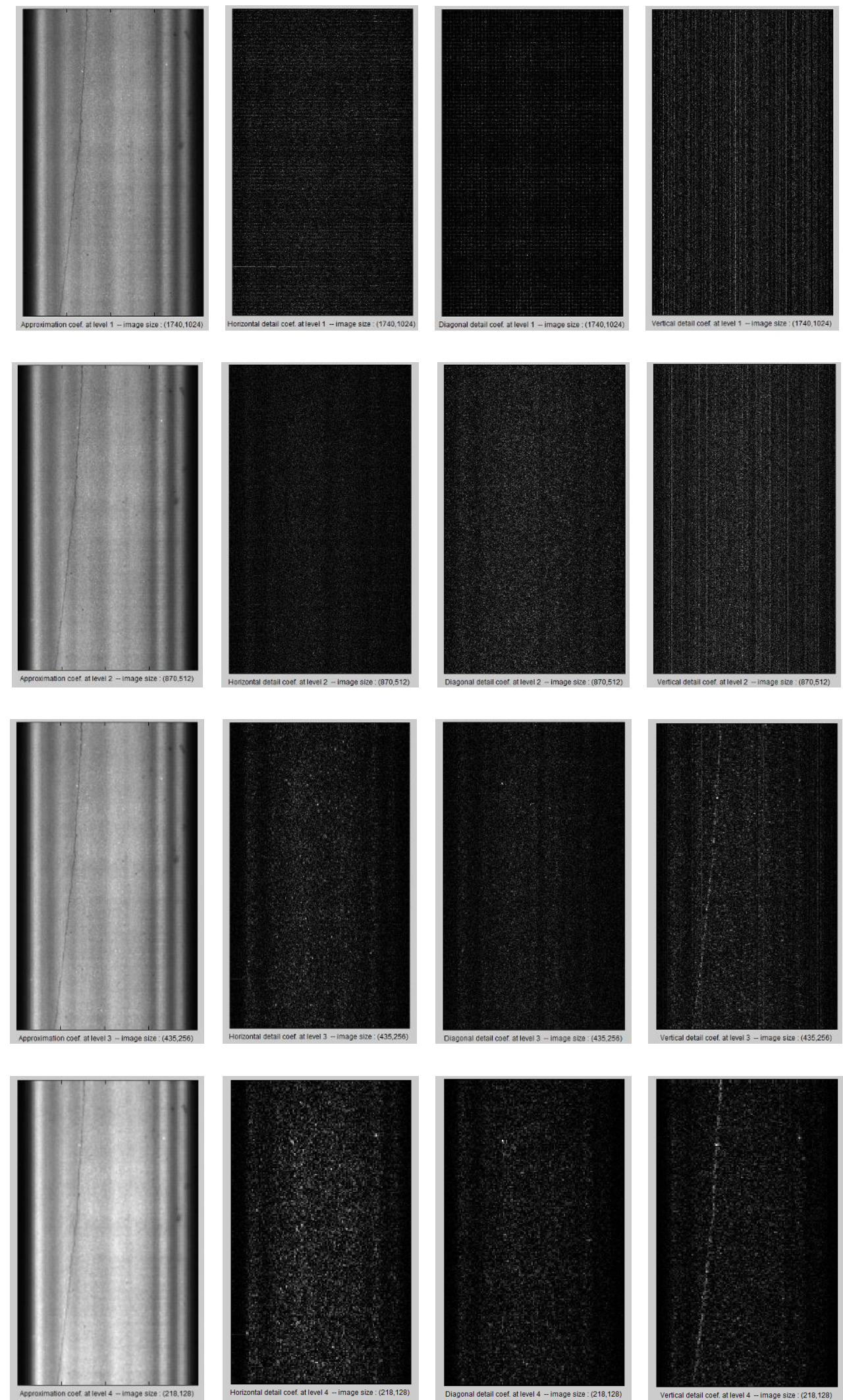

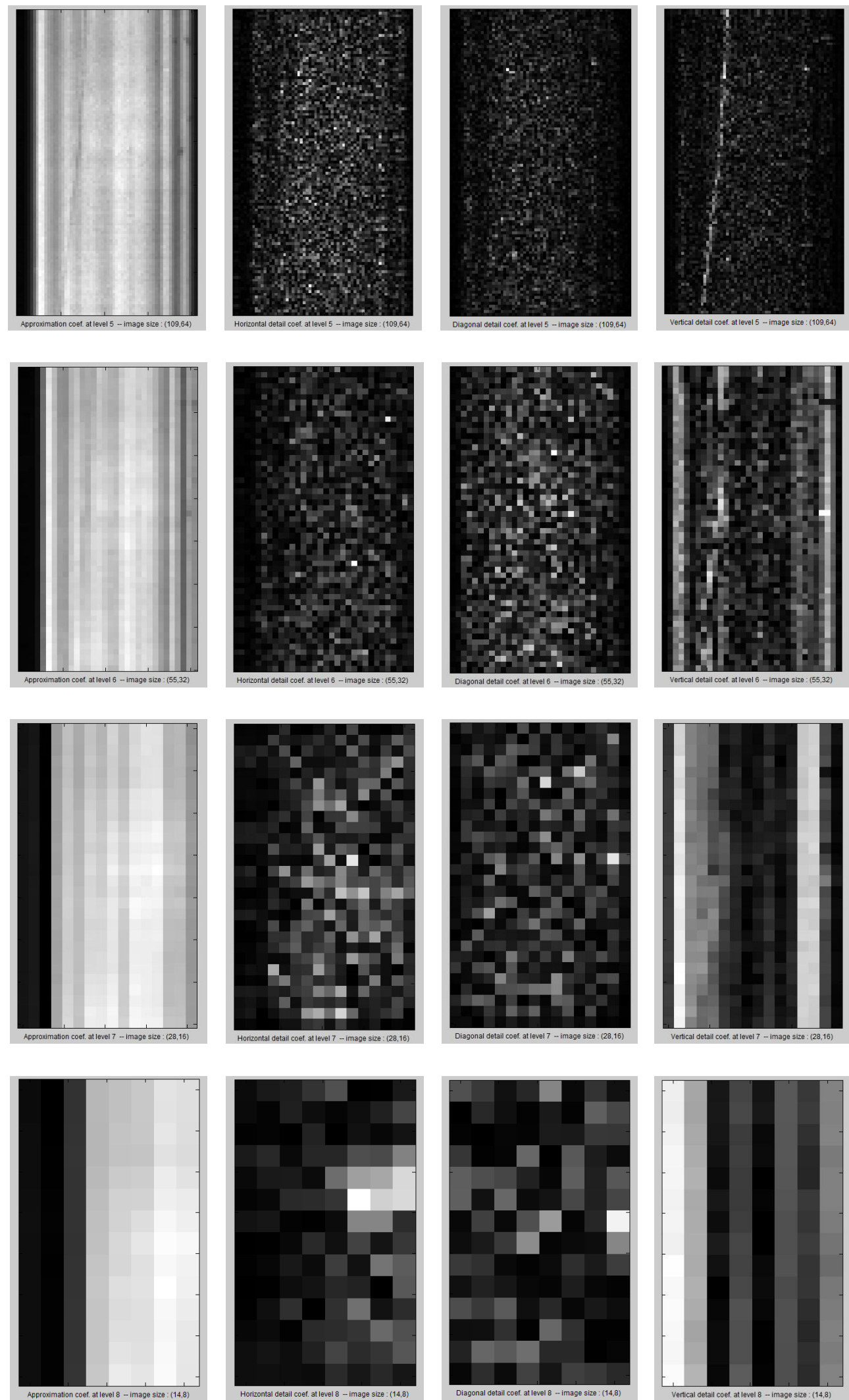

Figure 4 The enlarged images of the decomposition result in Fig. 3(a).(top-dowm:L1

to L8; left-right: Approximations, Horizontal Details, Diagonal Details, Vertical

Details) 


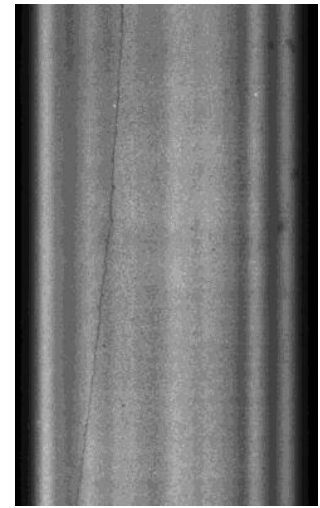

(a)

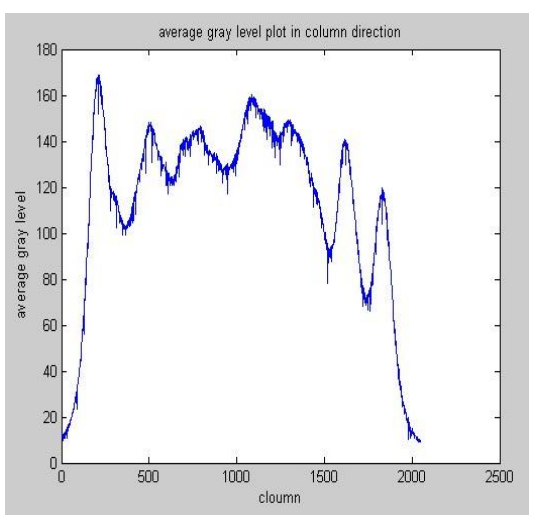

(b)

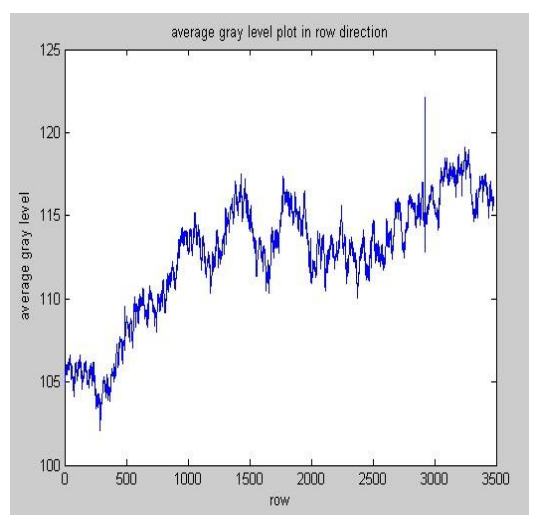

(c)

Figure 5. Original pavement image and the average gray level

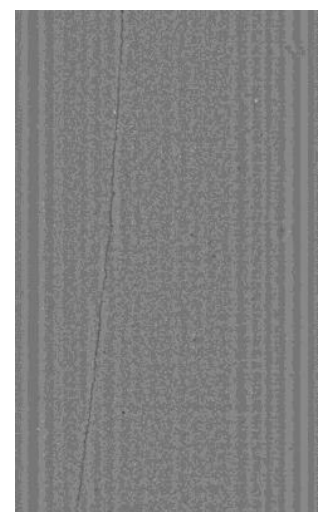

(a)

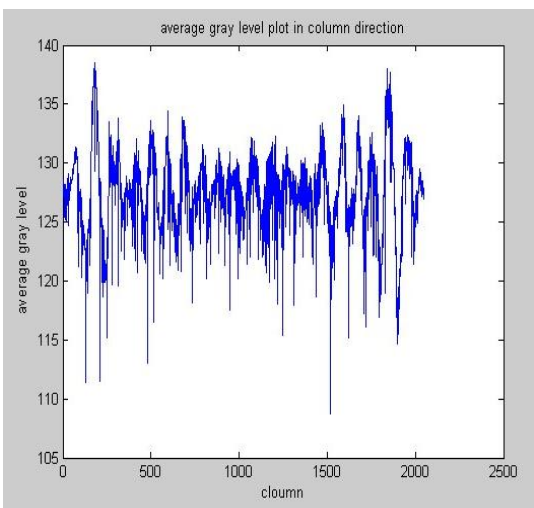

(b)

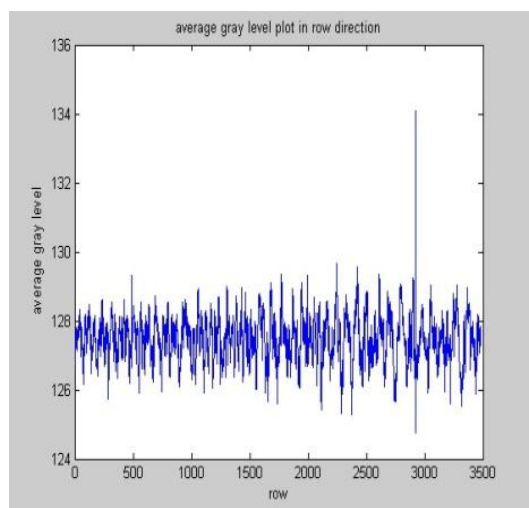

(c)

Figure 6. Uniform background pavement image and the average gray level

\section{Experimental Study}

In order to test the performance of the non-uniform background removal algorithm based on multi-scale wavelet transform, the two existing methods of obtaining the background in spatial domain including median filter and morphological closing are discussed. Four pavement images with a size of $2048 \times 3480$ pixels are selected for illustration purpose as shown in Fig. 7. The median filter with the size of $100 \times 100$, and close operation filter with the $30 \times 30$ square structuring element are selected in this paper. It is easily seen that the uniform background pavement image can be obtained by all the three non-uniform background removal algorithms. 

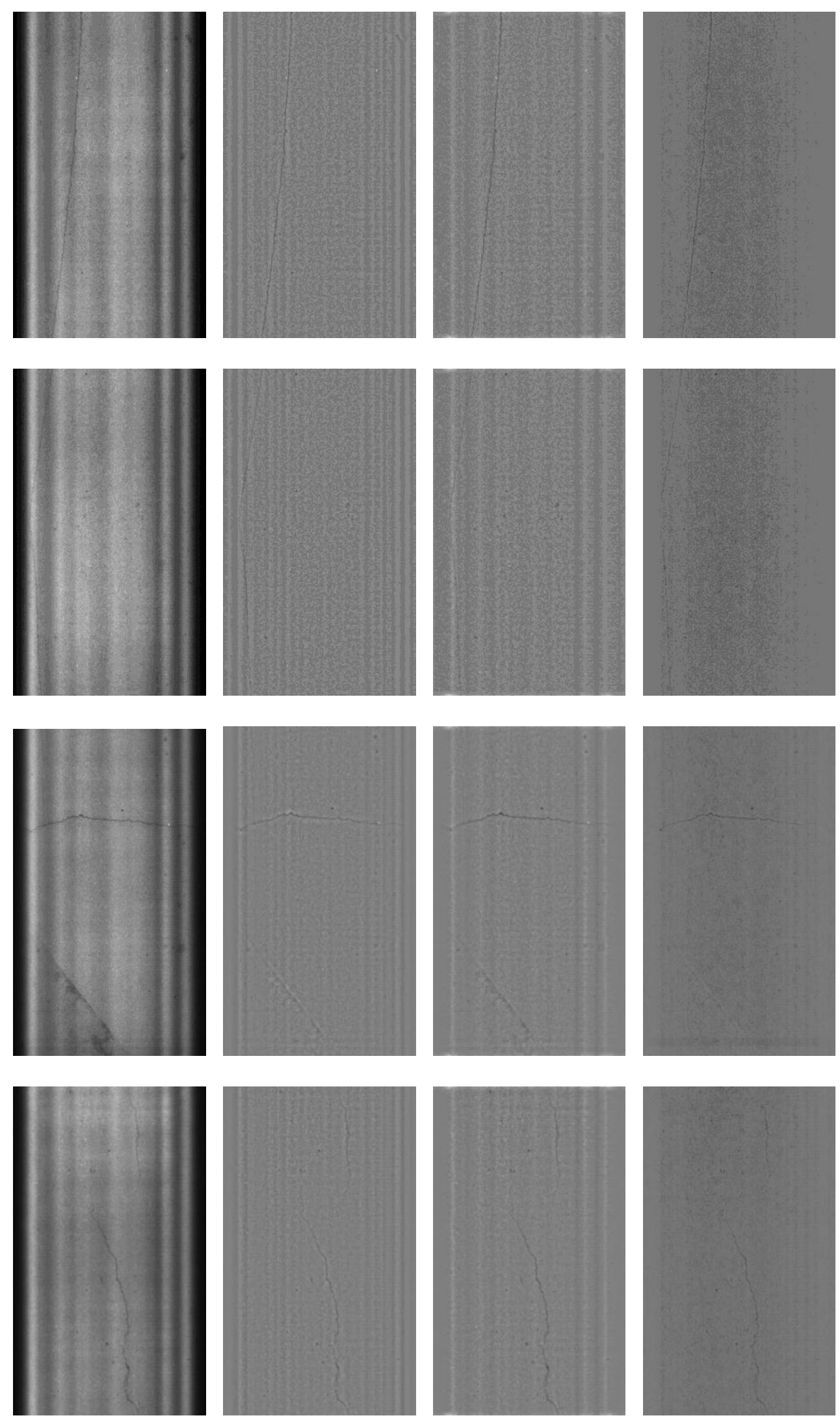

Figure 7. Pavement images before and after using the non-uniform background removal algorithms (top-down: image 1 to 4; left-right: original, multi-scale wavelet, median, morphological closing) 
To compare quantitatively the effectiveness of the proposed multi-scale wavelet transform algorithm with the other two non-uniform background removal algorithms, the standard deviation is selected to calculate the variation or dispersion from the mean of a pavement image. It is easy to understand that the uniform background pavement image has the smaller standard deviation compared with the original pavement image. The reduction degree of the standard deviation can describe the performance of removing the non-uniform background and it can be obtained by the following equations:

$$
R D=\frac{S T D_{0}-S T D}{S T D_{0}} \times 100 \%
$$

where $\mathrm{RD}$ is the reduction degree of $\mathrm{STD}, \mathrm{STD}_{0}$ is the standard deviation of the original pavement image, and STD is the standard deviation of the uniform background pavement image.

The standard deviation (STD), the reduction degree of the standard deviation (RD), and the program running time $(\mathrm{T})$ of the four experimental pavement images are shown in Tab.1. The performance of the three algorithms is similar from the visual, so they need to be compared by the quantitative method. The average reduction degree of the standard deviation of the four pavement distress images processed by the multi-scale wavelet transform algorithm, which is $82.0 \%$, is more than the median filter algorithm, which is $80.8 \%$, and the morphological closing, which is $81.8 \%$. The conclusion can be drawn that the performance of the multi-scale wavelet transform algorithm is in the first place among the three algorithms by using the index of the RD. The average running time of the multi-scale wavelet transform algorithm, which is $3.7 \mathrm{~s}$, is a little more than the morphological closing, which is $1.2 \mathrm{~s}$, and much less than the median filter algorithm, which is $17.7 \mathrm{~s}$. The conclusion can be drawn that the efficiency of the multi-scale wavelet transform algorithm is only in the second place 
among the three algorithms by using the index of the $T$. The efficiency of the multi-scale wavelet transform algorithm is reduced by $208.3 \%$ compared with the morphological closing algorithm, but increased by $378.4 \%$ compared with the median filter algorithm. In summary, the multi-scale wavelet transform algorithm is effective and efficient to remove the non-uniform background of the pavement images.

Table 1. Performance of different non-uniform background removal algorithms

\begin{tabular}{|c|c|c|c|c|c|c|c|c|c|c|}
\hline \multirow[t]{2}{*}{ Image } & \multirow{2}{*}{$\begin{array}{c}\text { Original } \\
\operatorname{STD}_{0}\end{array}$} & \multicolumn{3}{|c|}{$\begin{array}{c}\text { Multi-scale Wavelet } \\
\text { Transform }\end{array}$} & \multicolumn{3}{|c|}{$\begin{array}{l}\text { Median } \\
\text { Filter }\end{array}$} & \multicolumn{3}{|c|}{$\begin{array}{l}\text { Morphological } \\
\text { Closing }\end{array}$} \\
\hline & & STD & $\mathrm{RD}(\%)$ & $\mathrm{T}(\mathrm{s})$ & STD & $\mathrm{RD}(\%)$ & $\mathrm{T}(\mathrm{s})$ & STD & $\mathrm{RD}(\%)$ & $\mathrm{T}(\mathrm{s})$ \\
\hline 1 & 41.5 & 7.5 & 81.9 & 3.8 & 8.0 & 80.7 & 17.8 & 7.8 & 81.2 & 1.2 \\
\hline 2 & 44.1 & 7.6 & 82.8 & 3.6 & 8.1 & 81.6 & 17.5 & 7.8 & 82.3 & 1.2 \\
\hline 3 & 39.8 & 7.2 & 81.9 & 3.7 & 7.6 & 80.9 & 17.7 & 7.2 & 81.9 & 1.2 \\
\hline 4 & 38.7 & 7.2 & 81.4 & 3.8 & 7.7 & 80.1 & 17.8 & 7.1 & 81.6 & 1.2 \\
\hline Mean & 41.0 & 7.4 & 82.0 & 3.7 & 7.9 & 80.8 & 17.7 & 7.5 & 81.8 & 1.2 \\
\hline
\end{tabular}

To analyze how the pavement distress image non-uniform background removal algorithm influences the recognition of the pavement distress, the distress should be extracted from the pavement images firstly. The primary cue for pavement crack segmentation is that a crack is a thin strip of pixels whose intensities are appreciably darker than the surrounding background (Huang and $\mathrm{Xu}$ 2006). Thresholding is the simplest method to extract the crack for the pavement image with uniform background, and it can be used to create the binary pavement image from the gray scale image (Ying 2009). The pixel with the intensity which is less than the threshold value is considered as a crack seed, otherwise it is seen as background.

Fig. 8 shows the binary pavement images implemented by the thresholding. It is obvious that the crack is easily extracted from the uniform background pavement images by using the non-uniform background removal algorithm based on multi-scale wavelet transform and there is a lot of non-crack information in addition to the crack. 
Fig. 8 shows the binary pavement images after the non-crack information is removed. In order to compare the performance of the different pavement distress image non-uniform background removal algorithms, the number of pixels $(\mathrm{N})$ of objects in Fig. 8, the number of pixels $\left(\mathrm{N}_{1}\right)$ of objects in Fig. 9 , and the percentage $(\mathrm{P})$ of $\mathrm{N}_{1}$ in $\mathrm{N}$ should be counted and they are shown in Tab.2. The index of $\mathrm{N}_{1}$ represents the number of the crack pixels, and the larger value of $\mathrm{N}_{1}$ represents the more accurate crack extracted from the pavement image. The index of $\mathrm{P}$ means crack pixels in the proportion of the total pixels including the crack information and the non-crack information. The larger value of $\mathrm{P}$ shows that not only the more accurate crack information is obtained but also the less non-crack information is remained on the binary pavement image, and it is very convenient for the crack recognition. The average $\mathrm{N}_{1}$ of the four binary pavement distress images processed by the multi-scale wavelet transform algorithm, which is 23144 , is less than the median filter algorithm, which is 25310, but more than the morphological closing algorithm, which is 18959 . On the whole, the accuracy of the multi-scale wavelet transform algorithm is reduced by $8.6 \%$ compared with the median filter algorithm, but increased by $22.1 \%$ compared with the morphological closing algorithm. The average $\mathrm{P}$ of the four binary pavement distress images processed by the multi-scale wavelet transform algorithm, which is $24.9 \%$, is less than the median filter algorithm, which is $34.8 \%$, but more than the morphological closing algorithm, which is $18.1 \%$. The conclusion can be drawn that there is more non-crack information is remained on the binary pavement images processed by the multi-scale wavelet transform algorithm compared with the median filter algorithm, but the non-crack information is less than the morphological closing algorithm. The non-uniform background removal algorithm based on median filter seems to be the best algorithm for the extraction of the crack without 
considering the time factor. However, it is clear that the non-uniform background removal algorithm based on multi-scale wavelet transform has a better result than other algorithms for the extraction of the crack tip (the tiny crack) from Fig. 10. In order to analyze the crack tip easily, the crack tip is enlarged, and to ensure that there is comparability among the different non-uniform background removal algorithms, the crack tip on the pavement images processed by the different non-uniform background removal algorithms has the same start point (the red points) as shown in Fig. 10.

Table 2. Performance of different algorithms extracting cracks from pavement images

\begin{tabular}{|c|c|c|c|c|c|c|c|c|c|}
\hline \multirow{2}{*}{ Image } & \multicolumn{3}{|c|}{$\begin{array}{c}\text { Multi-scale } \\
\text { Wavelet Transform }\end{array}$} & \multicolumn{3}{c|}{$\begin{array}{c}\text { Median } \\
\text { Filter }\end{array}$} & \multicolumn{3}{c|}{$\begin{array}{c}\text { Morphological } \\
\text { Closing }\end{array}$} \\
\hline & $\mathrm{N}$ & $\mathrm{N}_{1}$ & $\mathrm{P}(\%)$ & $\mathrm{N}$ & $\mathrm{N}_{1}$ & $\mathrm{P}(\%)$ & $\mathrm{N}$ & $\mathrm{N}_{1}$ & $\mathrm{P}(\%)$ \\
\hline 1 & 102940 & 32493 & 31.6 & 82971 & 37038 & 44.6 & 131680 & 31948 & 24.3 \\
\hline 2 & 108950 & 18578 & 17.1 & 78453 & 13644 & 17.4 & 115728 & 6815 & 5.9 \\
\hline 3 & 73529 & 15450 & 21.0 & 63177 & 18210 & 28.8 & 91151 & 13822 & 15.2 \\
\hline 4 & 85800 & 26055 & 30.4 & 65970 & 32349 & 49.0 & 79832 & 23249 & 29.1 \\
\hline Mean & 92805 & 23144 & 24.9 & 72643 & 25310 & 34.8 & 104598 & 18959 & 18.1 \\
\hline
\end{tabular}



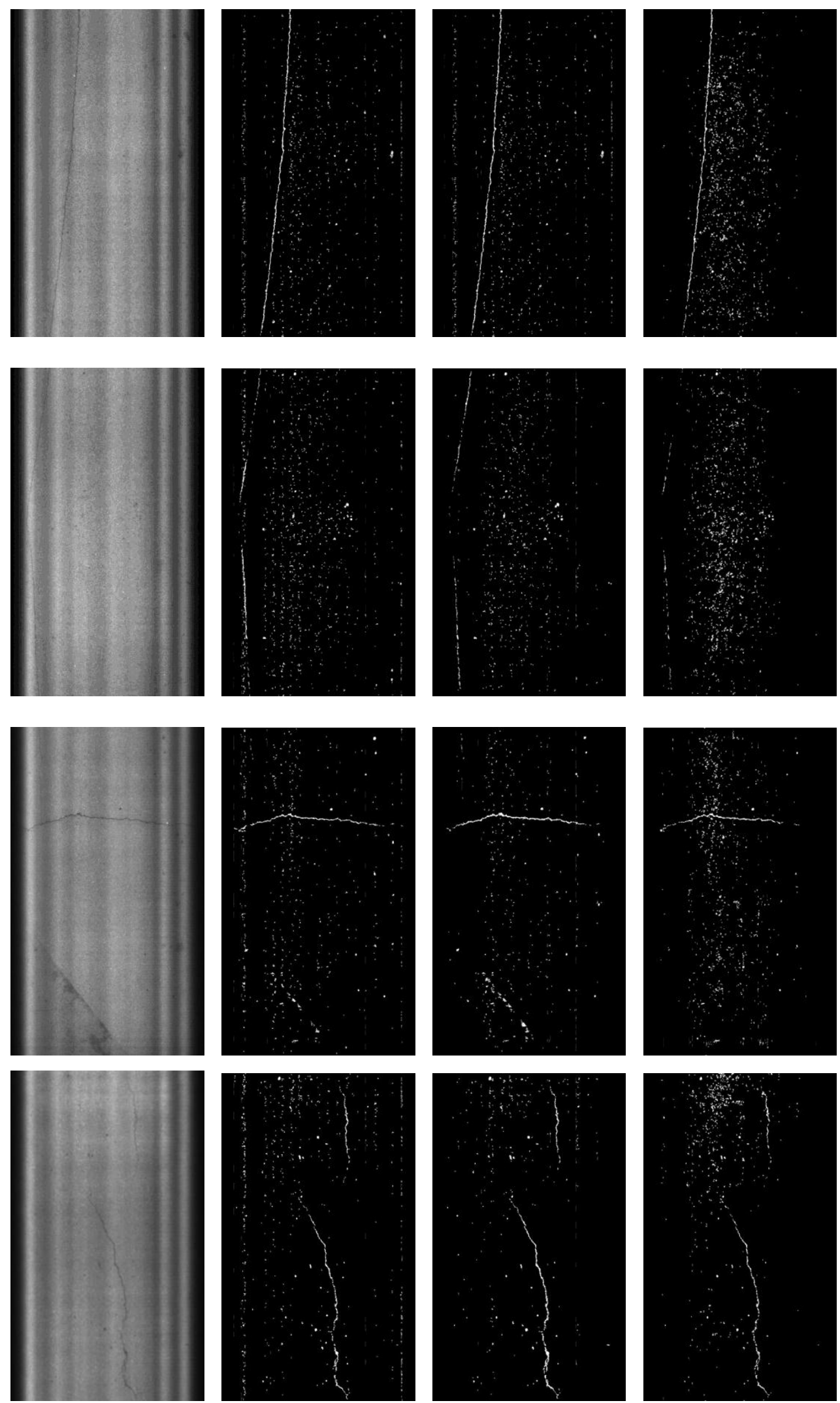

Figure 8. The binary pavement images (top-down: image 1 to 4; left-right: original, multi-scale wavelet, median, morphological closing) 

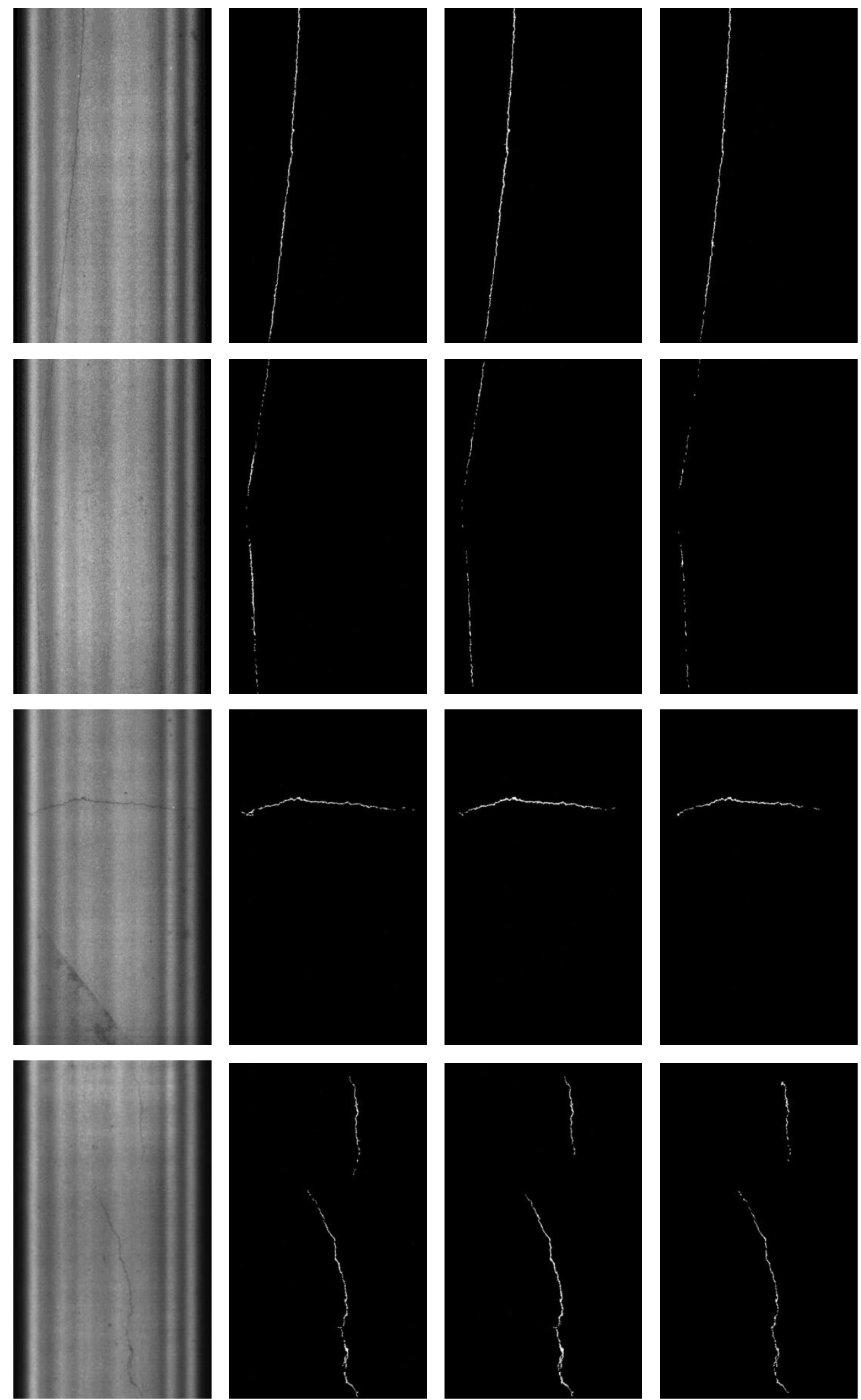

Figure 9. The binary pavement images after the non-crack information is removed (top-down: image 1 to 4; left-right: original, multi-scale wavelet, median, morphological closing) 

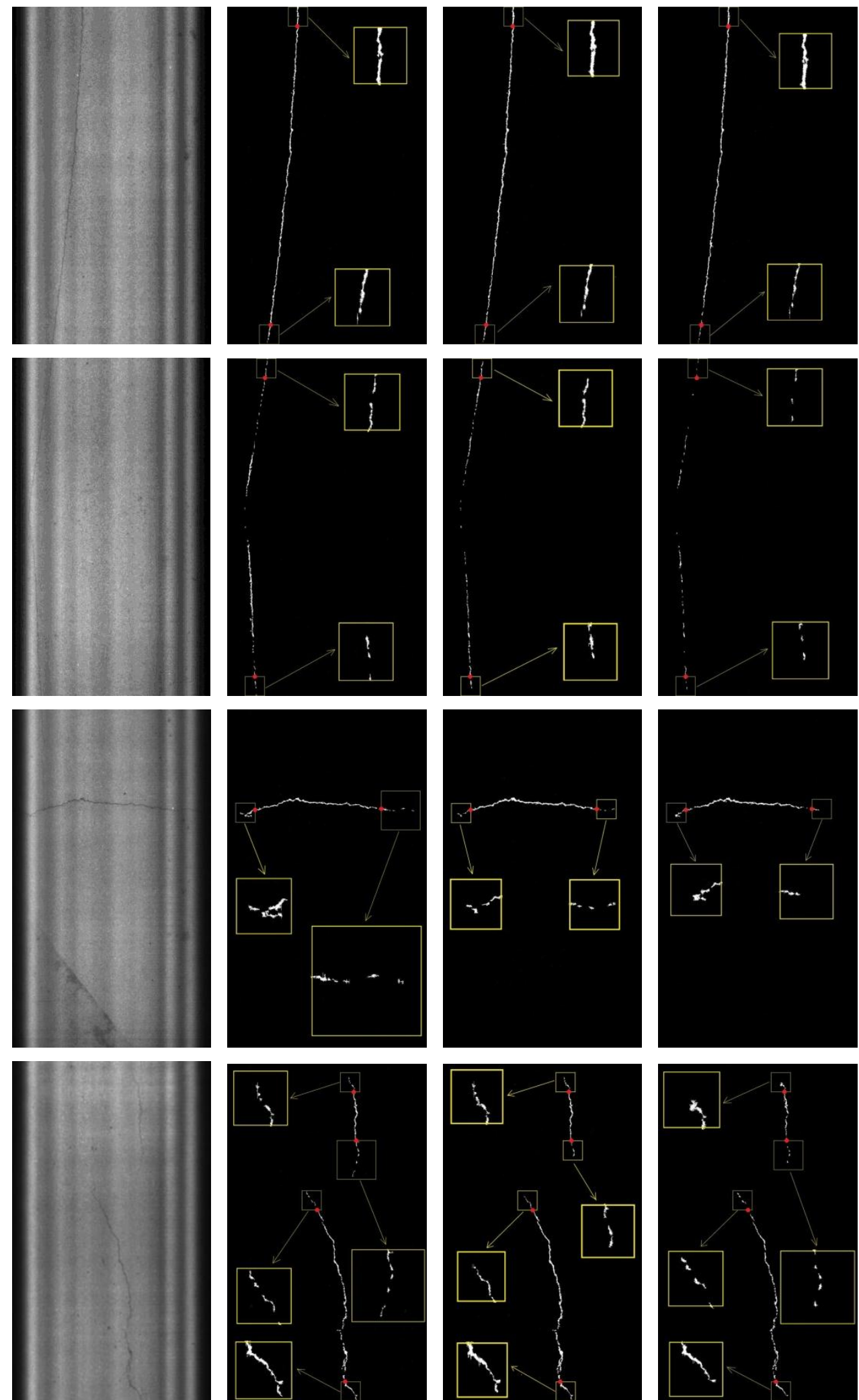

Figure 10. The crack tip (top-down: image 1 to 4; left-right: original, multi-scale wavelet, median, morphological closing) 


\section{Conclusions}

The pavement images with non-uniform background are always collected due to non-uniform distributed lighting condition, dirt on pavement surface and the shadow of obstacles, leading to the failure of pavement image segmentation and pavement distress identification easily. In this paper, a novel non-uniform background removal algorithm based on multi-scale wavelet transform is presented, and it mainly includes the acquisition and brightness correction of the pavement image background. The major component of the algorithm is obtaining the background using the multi-scale wavelet transform. The proposed algorithm is compared with the median filter algorithm and the morphological closing algorithm. Experimental results clearly demonstrate that the proposed algorithm can effectively remove the non-uniform background, and it has an advantage for the extraction of the tiny crack (the crack tip) compared with other two algorithms. In a word, the proposed algorithm is able to lay the foundation for the following pavement distress segmentation and recognition.

\section{Acknowledgement}

This study is sponsored by Shanghai PPD Transportation Science \& Technology LTD and in part by National Science Foundation of China under grants No. 51250110075 and U1134206, to which the authors are very grateful. The authors are thankful to anonymous reviewers for their insightful comments and constructive suggestions, which help us improve the content and refine the presentation of the original manuscript. 


\section{References}

[1] Acosta, J.A., Mullen R.L. and Figueroa, J.L. (2004). Pavement Surface Distress Evaluation Using Video Image Analysis, Research Project Progress, Case Western Reserve University, http://ecivwww.cwru.edu/civil/research/odotl.html

[2] ASTM D5340 (2004). Standard Test Method for Pavement Condition Index Surveys, Active Standard ASTM D5340, Volume: 04.03

[3] Charles, P. and Rosser, D. (2001). "Managing road agencies into the future", Road and Transport Research

[4] Cheng, H.D. and C. Glazier. Automated Real-Time Pavement Crack Deflection/ Classification System. NCHRP-IDEA Program Project Final Report. Washington, D.C., Transportation Research Board, 2002.

[5] Cheng, H.D. and M. Mivojim. Automatic pavement distress detection system [J]. Journal of Information Sciences, 1998(108):219-240.

[6] Cheng, H.D., Jim-Rong Chen, Chris Glazier, et al. Novel approach to pavement cracking detection based on fuzzy set theory [J]. Journal of Computing in Civil Engineering, 1999, 13(4): 270-280.

[7] Chung, H., Girardello, R., Soeller, T. and Shinozuka, M. (2003). "Automated management of pavement inspection systems", the SPIE 10th International Symposium on Smart Structure and Infrastructure Systems, March 2-6, San Diego, CA

[8] Chou, E. E.Salari. Transportation Informatics: An Image Analysis System for Managing Transportation Facilities-Phase II [R].2012.

[9] Ferguson, R., Pratt, D. and Macintyre, I. (1999). "Automated detection and classification of cracking in road pavements", Road and Transport Research 
[10]Georgopoulos, A., Loizos, A., Flouda, A. Digital image processing as a tool for pavement distress evaluation, Journal of Photogrammetry and Remote Sensing, Vol. 50, No. 1, 1995, 23-33

[11]Gunaratne, M., Mraz, A. and Sokolic, I. (2003). Study Of The Feasibility Of Video Logging With Pavement Condition Evaluation, Final Report BC-965, University of South Florida, www.dot.state.fl.us/research-center/ CompletedProj/ SummarvSMO/FDOT BC965_rpt.pdf

[12]Huang, Yaxiong, Bugao Xu. Automatic inspection of pavement cracking distress [J]. Journal of Electronic Imaging, 2006, 15(1), 013017.

[13]Huang, Y., Y. Tsai. Enhanced Pavement Distress Segmentation Algorithm using Dynamic Programming and Connected Component Analysis [A]. TRB 2011 Annual Meeting [C]. 2011.

[14]Huang, Y., and Xu, B. (2006). "Automatic inspection of pavement cracking distress", Journal of Electronic Imaging, Vol. 15

[15]Javidi, B., Stephens, J., Kishk, S., Naughton, T., MacDonald, J. and Isaac, A., (2003). Pilot for Automated Detection and Classification of Road Surface Degradation Features, Connecticut Cooperative Highway Research Program, Report No. JHR 03-293, November

[16]Kamaliardakani, M., Sun, L., and Ardakani, M.(2014). "Sealed-Crack Detection Algorithm Using Heuristic Thresholding Approach." J. Comput. Civ.Eng., 10.1061/(ASCE)CP.1943-5487.0000447,04014110.

[17]Koutsopoulos, H.N., B. Downey. Primitive-based classification of pavement cracking images [J]. Journal of Transportation Engineering, 1993, 119(3): $402-418$ 
[18]Kane, A.R. and Micozzi, M. (1996). "Managing roads in the 90's and beyond-views from the USA", Road and Transport Research, Vol. 5, No. 4,1996

[19]Lindly, J.K., Bell, F. and Uiiah, S. (2005). "Specifying automated pavement condition surveys", Journal of the Transportation Research Forum, Vol. 44, No. 3

[20]Mallat, Stephane. Multifrequency Channel decompositions of images and wavelet models [J]. IEEE Transactions on acoustics, Speech and signal processing, 37(12): 2091-2110, 1989.

[21]National Cooperative Highway Research Program. NCHRP Synthesis 334 Automated Pavement Distress Collection Techniques. Transportation Research Board, 2004.

[22]NSF. (1993). Civil Infrastructure Systems Research: Strategic Issues. National Science Foundation, Washington, D.C.

[23] Oh, H-k. (1998), "Automated pavement evaluation system for pavement distress assessment", Transportation Research Board Meeting, Washington, DC, January

[24] Salari, E., E.Chou, J.Lynch, et al. Transportation Informatics: Advanced Image Processing Techniques for Automated Pavement Distress Evaluation [R]. 2010.

[25]Smadi, O.G., McWaters, B.R., Jones, K.B., Gumbert, R.L., Krauel, R.M. and Maze, T.H. (1997). "Selection of automated pavement distress evaluation technology, Iowa DOT case study", presented at the $76^{*}$ annual meeting of Transportation Research Board, Washington D.C., http://www. ctre.iastate.edu/ pubs/conferences/smadi/

[26] Sivaneswaran, N. and Pierce, L.M. (2001) WSDOT Surface Distress Measurement Methods, http://hotmix.ee.washington.edu/wsdQt web/Modules/09 pavementevaluation/Q9-3_bQdy. htm 
[27] Sjogren, L. (2002). "State of the art: Automated crack measurement of road surface”, Research Project Report, Swedish National Road and Transportation Research Institute

[28]Sun, L., Kamaliardakani, M., and Zhang, Y. (2015). "Weighted Neighborhood Pixels Segmentation Method for Automated Detection of Cracks on Pavement Surface Images." J. Comput. Civ. Eng., 10.1061/(ASCE)CP.1943-5487.0000488, 04015021.

[29]Sun, Y., E.Salari, E.Chou. Automated Pavement Distress Detection Using Advanced Image Processing Techniques [J]. IEEE, 2009, 373-377.

[30] Sokolic, I., M. Gunaratne, A. Mraz, and A. Nazef. Evaluation of Pavement Distress Imaging Systems. Presented at the 83d Annual Meeting of the Transportation Research Board. Washington, D.C., Transportation Research Board, 2004.

[31]Wang, K.C.P. and Elliott, R.P. (1999). Investigation of Image Archiving for Pavement Surface Distress Survey, Report-1072, University of Arkansas

[32] Wang, K. (2000). "Design and implementation of automated system for pavement surface distress survey”, Journal of Infrastructure Systems, Vol. 6, 1, 24-32

[33]Wang, K.C.P. (2003). Automated Pavement Distress Survey Through Stereovision, in An Annual Progress Report for NCHRP IDEA Program, Transportation Research Board, National Research Council, Washington D.C.

[34]Ward, M.O., El-Korchi, T., Norman Wittels, and Gennert, M.A. (1992). "Pavement image processing systems: an engineering approach", in ASCE Road and Airport Pavement Response Monitoring Systems, Janoo, V.C. and Eaton, R.A. (eds.), American Society of Civil Engineers, New York

[35] Ying, L.. Beamlet Transform Based Technique for Pavement Image Processing 
and Classification [J]. IEEE, 2009,141-145.

[36]Zhou, J., P. S. Huang, F. P. Chiang. Wavelet-based pavement distress detection and evaluation [R]. Proceedings of SPIE Vol. 5207.728-739, 2003. 